\title{
REDAKTIONEN HAR MODTAGET
}

BLOK, ANDERS \& CARSTEN BAGGE LAUSTEN (red.): Sociologiens problemer. En grundbog. København: Hans Reitzels Forlag 2019. 792 sider. ISBN 97887-4126-714-2. Pris: 510 kr.

COLLIN, FINN, DAVID BUDTZ PEDERSEN \& FREDERIK STJERNFELT: Menneskebilleder. Et analyseredskab. København: Hans Reitzels Forlag 2019. 200 sider. ISBN 978-87-4127-731-8. Pris: $300 \mathrm{kr}$.

RASMUSSEN, JON DAG: Ældre på samfundets underflade. Frederiksberg: Forlaget Frydenlund 2019. 199 sider. ISBN 978-87-7216-101-3. Pris: 299 kr.

SALAZAR, JUAN FRANCISCO, SARAH PINK, ANDREW IRVING \& JOHANNES SJÖBERG (eds): Anthropologies and Futures. Researching Emerging and Uncertain Worlds. London: Bloomsbury Anthropology 2017. 281 sider. ISBN 978-14-7426-487-7. Pris: $£ 20$ (pb).

SHEPHERD, CHRISTOPHER J.: Haunted Houses and Ghostly Encounters. Ethnography and Animism in East Timor, 1860-1975. København: NIAS Press 2019. 345 sider. ISBN 978-87-7694-267-0. Pris: £ 25 (pb). 